\title{
AN EXAMINATION OF SOCIO-ENVIRONMENTAL PROBLEMS FACED BY AGRO-INDUSTRIES AND NEIGHBOURHOOD SETTLEMENTS IN CAMEROON: THE CASE OF CAMEROON DEVELOPMENT CORPORATION (CDC) IN FAKO DIVISION, SOUTH WEST REGION
}

\author{
Norah Aziamin Asongu Ph.D ${ }^{1}$, Ngoe Fritz Eseokwea Ph.D ${ }^{2}$ \\ ${ }^{1}$ Researcher/Anthropologist, Department of Economics and Environmental studies. National Centre \\ for Education, Ministry of scientific Research and innovation, Yaounde Cameroon \\ ${ }^{2}$ Researcher/ Economist, Department of Economics and Environmental studies. National Centre for \\ Education, Ministry of Scientific Research and Innovations, Yaounde Cameroon
}

Article DOI: https://doi.org/10.36713/epra7347

DOI No: 10.36713/epra7347

\begin{abstract}
This study was carried out in Fako Division of Cameroon's South West Region with the objective of identifying the social and environmental problems created by Cameroon Development Corporation (CDC), the country's largest agro-industrial cooperation which is next employer to the government. Fako Division was selected for the study because all the major settlements in the Division have been affected by activities of CDC. Methods of data collection were qualitative using interviews, focus group discussions, and direct observation in the workers camps and third party settlements. Results of the study indicate that despite the corporation's contribution to employment; environmental and social problems attributed to the company's activities remain the greatest cause for concern affecting other human activities in the affected settlements. Deforestation and destruction of the ecosystem, untreated effluent discharged into the environment, gaseous emissions, noise pollution and aerial sprays in plantations including problems of hygiene and sanitation were identified among major problems affecting human settlements in the affected areas. Furthermore poor housing conditions, congestions, inadequate disposal of sewage and waste have been identified as greatest sources of social and health problems affecting the workers camps. The study calls for government and its agencies to conduct environmental impact and social assessment studies where the impacts could be measured to ascertain the effects on the environment and populations affected by the activities of the corporation.
\end{abstract}

KEY WORDS: Agro-industries, neighbourhood-settlements, Cameroon Development Corporation, social problems, environmental problems.

\section{INTRODUCTION}

The Cameroon Development Corporation (CDC) is the largest agro-industrial complex in Cameroon. Its place in the history of Cameroon is significant as it plays a major role in social, economic and even infrastructural developments in the country; especially the Anglophone regions. It is with this justification that in the early days of independence President Ahidjo the president of Federal Republic of Cameroon described CDC as "a State within a state" as the corporation has special affections of populations from all socio professional groups in Cameroon. The Cameroon Development Corporation
(CDC) as from January 1947 took over from West African Plantation Victoria (WAPV) and African Fruit Company (AFC) owned by the Germans. The CDC ordinance was tabled in Lagos the then capital of Nigeria by Mr F.E.V Smith who became the corporation's first chairman. Thereafter the corporation became property of Commonwealth Development Corporation (CDC), set up under the auspices of British post-war labour government. The name CDC was therefore born to replace the former German plantations. When French Cameroon gained independence in 1960 and West Cameroon was granted independence by joining French Cameroon 
under a federation, the company was still managed by the British government. The Commonwealth development corporation continued to manage the affairs of $\mathrm{CDC}$, alongside other Commonwealth businesses for fourteen years (1960-1974) and handed over to Cameroon whereby the name Cameroon Development Corporation was adopted with the same abbreviation (CDC). The Cameroon Development Corporation is now a parastatal owned by the state of Cameroon with head office in Bota-Limbe. The plantation covers a total of approximately 42,027 Hectares of land, 38,000 Hectares of mature plantations at production stage. Rubber plantations covers $22,262 \mathrm{Ha}$ of land while oil palm covers 15,240 Ha and bananas 4,525 Ha. The corporation constitutes a workforce of close to 22,036 employees including temporal workers, ranking it the second highest employer after the state of Cameroon. CDC produces averagely between 18,000 and 20,000 tons of rubber, 18,000 - 19,000 tons of palm oil, 600 tons of palm kernel and an average of between 90,000 and 110,000 tons of bananas annually (CDC, 2017)

The establishment of Cameroon Development Corporation in Fako Division has led to its occupation of vast portions of forest land used for agriculture for cultivation of mainly industrial trees. According to the Ministry of State Property and Land Tenure (2008) the corporation occupies more than half of the land mass in Fako Division. Vast areas of land meant for food production have been affected by deforestation, deprivation and dispossession of land holdings from indigenous communities drawing a similarity to the situation in Columbia, Malaysia, Brazil, Nigeria, and Congo with loss of biodiversity (Oyono, 2005). This is often done without sustainable compensation to communities including towns and villages which have been affected by activities of the industrial tree estates. Deforestation and replacement of diverse ecosystems by this large-scale monoculture continue to deprive local populations of the products and services they obtain from the forest while the use of agrochemicals increasingly affect local populations as well as their ecosystems as observed in most areas of Fako Division like Limbe, Tiko, Mondoni, Idenau Mutengene, Buea, Ekona, and Ekondo titi.in Ndian division (EMIS, 2010-2013).

The greatest predicament attributed to the presence of industrial tree estates in these settlements is environmental problems affecting land, air and water attributed to gaseous emissions and effluent discharged into the environment. In addition, the multiplier effects attributed to the impact of the ITPs; notably the CDC among other monocultures have been the reduction of food supply from peasant populations (who have been deprived of arable land), limit to expansion of human settlements as witnessed in other tropical countries which harbour monocultures. In Cameroon, legal rights to land given to Industrial Trees Plantation (ITPs) empowers them to confiscate land and displace local communities without state intervention because all land legally belongs to the state (Oyono, 2005; EMIS 2010- 2013). Indigenous communities located around ITPs tend to have limited areas of land for agricultural activities and for expansion of human settlements thereby creating potential sources of conflict between the peripheral settlement and ITPs.

According to Baromey et al; (2012) large scale industrial tree plantations are expected to inject part of their revenue from extractive activities to support economic growth and development in neighbourhood settlement and the country as a whole. Meanwhile studies by Martinez (2002) in Brazil support that most agro industries fail to adequately support local communities in the extractive zones to reduce social costs incurred as a result of the activities of extractive industries. The quest for social benefits and inability of extractive industries to comply with the demands of the affected settlement have been the greatest sources of violent confrontations between the affected communities and the industrial tree plantations as witnessed in Cameroon (1947 and 2012), Malaysia (1990), Indonesia (1978) and Nigeria (2007), Thailand (1967-90) including a host of other countries in the Global South (Economic and political weekly, 2010). Unfortunately these demands have always been welcome with reprisals from state authorities without compelling extractive industries to adequately reduce social costs to the affected populations.

According to Ingram et al; (2014), the development of oil palm plantations has also resulted in deforestation and other negative environmental impacts, such as poor water quality in areas where effluent and other waste products from factories are directed into water used for drinking and household uses, air pollution where gaseous emission from factories affects human activities and soil degradation resulting from overuse of land resources. Reducing environmental damage and creating better conditions for the productive engagement of local communities are major challenges for plantation investment in forested frontier regions. According to studies by Asaah et al (2011), EMIS (2013), employment opportunities offered to indigenous people for land loss are of low quality due to low wages, which are hardly able to compensate adequately for loss of land and its sustainable resources.

\section{Objectives of the study}

This study seeks to;

(1) Examine the effects of $\mathrm{CDC}$ activities on the livelihood of communities in the study area

2) Identify the major environmental and social problems encountered in human settlements. 


\section{MATERIALS AND METHODS Study Area}

The South West region of Cameroon is located on the western fringes of the country along the coast of West Africa sharing coastal and land boundaries with Cross river state of Nigeria. The region lies between latitude $5^{\circ} 12$ North and longitude $9^{\circ} 18$ East of the Greenwich meridian (Aquah et al; 2014). Based on Cameroons' 2005 census the South West Region has a population of $1,481,433$, occupying a surface area of 25,410 square kilometres with a population density of 45.38 persons per square kilometre (45.38 persons $/ \mathrm{Km}^{2}$ ). The region comprises of six Administrative Divisions namely: Fako, Meme, Ndian, Manyu, Kupe Manenguba and Lebialem.

\section{Vegetation and Relief}

The South West Region belongs to the forest agro ecological zone of Cameroon. It is characterized by thick evergreen forest, high rainfall, high temperatures, and relative humidity. The region contains four mountains which share similarities in climate and relief to the western highlands; that is, the North West and West regions. They include Mount Cameroon (4100 m), Manenguba (2396m), Koupé (2059) and the Rumpi hill (1885m). The slope of Mount Cameroon is cultivated up to $1100 \mathrm{~m}$ because of its volcanic fertility which favours the growth of both export and food crops for domestic consumption (Njukwe et al, 2014). These volcanic soils have attracted the cultivation of industrial trees by the Cameroon Development Corporation which has occupied vast areas of land in Fako Division to the extent that livelihood sources in the human settlements have been greatly affected in the Division.

The South West Region has two seasons; a prolonged rainy season from mid-March to midNovember, and a dry season from mid-November to mid-March. Annual average rainfall in the region is $3000 \mathrm{~mm}$. Dibuncha situated along the west coast records the second highest rainfall in the world with an annual average of $5000 \mathrm{~mm}$ and maximum and minimum temperatures ranging from $38^{\circ} \mathrm{c}$ and $10^{\circ} \mathrm{c}$ respectively (Njukwe et al.., 2014). The relative humidity of the region is very high during the rainy season and varies from $70^{\circ} \mathrm{c}$ and $80^{\circ} \mathrm{c}$. Its hot climate is influenced by hot currents from the Atlantic Ocean. Meanwhile temperatures at high attitude areas such as Buea, Bangem, Alou, DikomeBalue, and KoupéManenguba that share similar relief; climate and soil types with the western highlands are relatively cold. These areas of the region grow similar crops like the West and North West Regions.

\section{Soils}

The region is characterized by soft, black, red, stony, sandy soil which is heavily leached during rainy season. The soils support the cultivation of a variety of food and export crops (Ebenezar et al., 2013).

\section{ECONOMIC ACTIVITIES Agriculture}

Agriculture is the major occupation of the people in the South West Region. The main agricultural activity is crop farming dominated mostly by small holdings for both export crops and food crops. The type of crops produced can be grouped into cereals (corn, groundnuts, beans); tubers (coco yams, yams, cassava, and potatoes) which are staples), tree crops (plantains, banana, palm trees, mangoes, oranges, guava, plum, pawpaw, lime, lemon) and vegetables. The major export crops produced in the region include cocoa, coffee (mangiferaindica), banana (Musa ssp, tea (Camellia sinensis), rubber (Heveabrassiliences), and oil palm (Elaeisguineensis). Although most of the south west region supports the cultivation of these crops by corporations and peasant farmers, most of these crops cannot be produced in a vast area of Fako Division due to the presence of industrial tree plantation corporations which have deprived, disposed and displaced majority of peasants from their land holdings, thus greatly affecting their livelihood sources (Ngoe, 2020).

\section{Commercial Activities}

There are no manufacturing industries in the South West Region. Trading is carried out with imports from Nigeria which shares both land and maritime boundaries with the region and also manufactured goods from Douala, the country's major industrial and manufacturing centre. Other trading activities are done with agricultural produce from rural areas to urban centres where there is evergrowing demand. Commercial activities are greatly hampered by poor road infrastructure which prevents effective distribution of goods and services, especially food items for domestic consumption like root and tuber crops, fruits and vegetables which are highly vulnerable to postharvest losses. Some of the goods traded in the region include imported food, textiles, drinks, electronic equipment, machinery, spare parts, meat, and frozen chicken, most of them imported from western countries and Asia.

\section{Fishing}

Fishing in the South West region is mostly done in the maritime areas of the west coast areas of Fako Division and the Bakassi peninsula in Ndian Division. Fishing on rivers has been greatly hampered by the presence of waterfalls and cataracts which impede movement of fishing boats and canoes. The main rivers in the region are Ndian, Meme, Manyu and Mongo. 


\section{FAUNA AND FLORA Fauna}

The following indigenous animals of the equatorial rain forest origin are available in the forests of the region: chimpanzees, monkeys, gorillas (cross river gorilla and western lowland gorilla), porcupines, deer, Duiker, cutting grass, hare, rat mole and insects ( Ajayi et al,, 2015), most of these animals are located in areas or forests which have not been tempered by human activities. Studies by Ajayi (2015), support that these animals migrate from areas with extensive human activities such as logging, bush burning and deforestation in general because of the destruction of their natural habitat. Birds identified in the South West forest include the white-necked pigeon (Columbia), Green breasted bush-strike (Malcanottus gladiators), necked picarthartes (Picathortesoreas) etc., reptiles and amphibians. Species of fauna include frogs, toads, lizards, chameleon, large frogs such as Conrauarobusta, Trichobastrachus robots in forests of Dikome Balue and Bosunga Balue in Ndian Division. Crocodiles, alligators and fish are found in big rivers notably the mungo, Meme, Ndian, and Manyurivers including the Atlantic Ocean. Other fauna include the pythons, vipers, and green snakes (Ajayi et al.(2015). There is massive migration of these animals from deforested zones to those areas not affected by human activities in the region.

\section{Flora}

Indigenous plants are many including some rare species which have been located in the forest reserve areas in the region. Trees are used as source of wood for energy, construction, furniture and for medicinal and food purposes. A large number of forest trees bearing fruits and seeds used for food, medicines and cultural rights exist in the forests of Manyu, Ndian, Kupe Manenguba, and Meme Divisions (Daniel et al., 2016). Most of these trees and plants species are growing extinct in parts of Fako Division like Tiko and Limbe Subdivisions due to large scale deforestation by Industrial Tree Plantations(ITP) and small scale farming on both export and food crops. The plant species include "njangsa" (Ricinodendronheudelotii), "white peper" (Piper nigrum), "country onion" (Afrostyraxlepidophyllus), "bush mango" (Irvingiagabonensis), "bitter kola" (Garcinia kola) and safou (African plums) (Dacryodesedulis). The trees are only found in forests of Meme, KupeMwanenguba, Ndian, Manyu and parts of Lebialem Divisions. Most of these trees have been threatened with extinction by human activities notably deforestation and logging and efforts are being made to domesticate them through agro forestry (Daniel et al., 2016). Other common species of trees found in the region include mahogany, iroko, sappele, bobinga, buma etc. Most of these trees have domestic uses and are of highly demand for timber export to the industrialized countries (Garity, 2014; Dawson et al., 2013).

\section{DATA COLLECTION \\ Primary Data Sources}

Primary data was obtained by organising working sessions using interview guides with officials of council areas affected by the Industrial Tree Plantations (CDC), organising working sessions using focus group discussion guides with village heads, notables and traditional authorities. Field workers were also randomly interviewed during work period in the plantations while they were purposely selected in the workers camps. Qualitative information was obtained through hanging out with workers in their camps where observation was done with respect to hygiene and sanitation, sources of water supply, areas of sewage and waste disposal, health facilities, recreational facilities, toilets, and schools.

\section{Secondary data}

Secondary data was obtained through documentation of existing literature on $\mathrm{CDC}$ obtained from the corporations head office in Bota-Limbe and review of literature related to industrial tree plantations on journals, textbooks, and websites. It also entailed a review and analysis of relevant theories, concepts and empirical facts generated from other research findings on industrial tree plantations, including information on gender issues in the corporation's documentaries.

\section{RESULTS AND DISCUSSIONS Examination of CDC effect on socioeconomic activities/human populations}

Most communities in Cameroon depend on the forest resources for means of livelihood. The forest is used for hunting, energy sources from wood, medicine, construction works, cultural activities and agriculture. In this study a series of activities were affected in the human settlements and workers residential areas. Most workers camps and other human settlements are surrounded by the CDC plantations as observed in Tiko, Limbe, Mutengene, Buea, Ekona, Idenau and Mondoni areas. According to respondents the activities of CDC affects its workers living conditions and third parties. Poor living conditions observed in workers camps have been responsible for the mass exit of workers from camps to neighbourhood settlements as experienced in Tiko, Limbe, Batoke and others. Population pressure in Tiko has been responsible for the construction of homes in marshy and unwholesome areas around the seashore. In Limbe the same population pressure has been responsible for construction of houses on hills and other high risk 
areas officially forbidden for human habitation in Cameroon because of inadequate land for housing resulting from CDC occupation. The situation is not different in Mbonge where the town has been completely surrounded by the CDC rubber plantation. Forests are very far from the workers camps and other settlements with the result that people especially the urban poor who still depend on forests for livelihood means trek for long distances in search for farmlands. The most precarious situation is that the few available areas for agriculture are not motorable. People have to carry food and wood for long distances from farms to their homes.

It was observed that recreation facilities are seriously lacking, especially for junior staff, women, and youths living in most of CDC workers camps. According to respondents' boredom and overuse of alcohol, sex and drugs are common in most workers camps; while casual and commercial sex has been commonly aggravated by low incomes and generalised poverty in the camps. Casual and commercial sex in camps has aggravated the incidence of sexually transmitted diseases (STDs) like HIV/AIDS among others. Most infrastructures for recreation like table tennis, swimming pools, and clubs are meant for high income workers like managers, engineers, and medical doctors including other skilled workers in the high income brackets. It was observed that low income workers have no access to such facilities especially as they are not located within their vicinity.

\section{Effect on sources of energy}

Energy sources available to urbanites include electricity and wood. Most of the rural areas lack electricity supply. Where electricity is available it is only limited for lightening of homes and refrigeration as residents are unable to afford to use the modern source of energy for cooking. Consequently most urbanites still depend on wood energy for cooking as only a limited number of household can afford the use of gas and electricity for cooking and other chores. It was observed that workers camps suffer from endemic energy problems as most camps are not supplied with electricity and worker depend on lantern sand candles for lightening homes. Giving that income level of the plantation workers are generally low, most workers use dry branches of rubber or palm for cooking when wood is inaccessible. Deforestation has led to increase cost of wood for population in urban areas, workers camps and rural areas affected by activities of the Cameroon Development Corporation in Fako Division.

\section{Destruction of flora and fauna}

Cultivation of food in most of Fako Division is on marginal land or patches of land left uncultivated by the CDC and other actors in deforestation. According to respondents the Cameroon
Development Corporation have reserve land for future plantation expansion that could benefit communities and relieve them from energy and food supplement but forbids workers and third parties from harnessing resources from these reserve lands for their well-being. Most often legal action is taken against any individual or group who trespasses in the reserve land. The corporation usually destroys food crops planted by residents on marginal lands and reserve areas without notification to the farmers. As a result of these unchecked human rights abuses by the corporation there is limited food supply in the study area and, high cost of food as most food items consumed in cities like Limbe, Tiko, and Buea are brought from other parts of the South West Region, North West and from those areas of Fako Division which have not been affected negatively by the activities of the corporate farmers. In the same vain other food items like bush meat are hardly found in the deforested areas of the Division. The destruction of fauna resulting from abusive deforestation by industrial tree plantations have made many animals and birds and snakes extinct in most parts of Fako Division. Migration of these animal species which used to serves as source of meat has caused increased in the cost of bush meat as only privileged households can afford. To counter some of the negative effects of food shortages in Fako some residents are getting engaged in urban agriculture where food crops are cultivated on marginal patches of land left by the CDC and animal husbandry like poultry farming, piggery and fish farming.

\section{Effects on expansion of settlements}

One of the greatest problems resulting from unchecked expansion of agro industries in Cameroon is the negative impact on urban expansion and high cost of building land, building materials and accommodation. In Fako Division the disappearance of forests as a result of deforestation has affected the construction of low cost wooden houses due to the high cost of wood. Most of the wood used for construction is brought from distant forests and other areas of the South West Region. According to studies by Ngoe and Yaya (2016) on Improving Urban habitat in Cameroon, the cost of building wooden structures and even furniture has increased tremendously that most people prefer to construct cement bricks houses than wood houses which were relatively cheaper for most income groups in the municipality. The same study advised that to prevent the escalating cost of building land and rental accommodation the Fako councils should pressurize CDC to give up some of its land holdings for urban expansion. In a focus group discussion in Mondoni village it was revealed that $\mathrm{CDC}$ released part of the land for expansion of the village due to increasing population but the land was all sold to rich and 
privilege individuals leaving those in the low income bracket with no plots of land.

\section{Deforestation and traditional health care}

According to World Health Organisation (2013) about $80 \%$ of inhabitants of African countries depend on traditional medicines for the treatment of most diseases. This dependence on traditional medicines may not necessarily be as a result of poverty and inability to afford modern medical treatment. It is believed that there are several diseases and illnesses that cannot be contained by modern medicines in villages studied. In Tiko and Moquo, the herbicides and pesticides used by CDC has led to the disappearance of plants species which were used for the treatment of diseases in the area. Some plants like yellow leaves used as blood medicine, fever grass use for the treatment of fever and enangaijoh which is used for the treatment of ring worm and other skin diseases etc. are extinct and cannot be found in the community again.

This means that deforestation and destruction of vast ecosystems is affecting the continents healthcare delivery system. The destruction of both flora and fauna as a result of expansion of corporate farms will spell devastating consequences on the health of consumers of traditional medicines unless adequate steps are taken in the continents domestic policies and strategies. Traditional medicines embody the use of both plant and animal species while their absence will affect most practices and create unemployment among the practitioners. In Fako Division deforestation has affected the practice of traditional medicines in most indigenous settlements. According to some respondents in Moquo village in Mondoni there are no indigenous practitioners of traditional medicines in the village. They testified that most traditional healers have died without passing on the knowledge to their children or relatives due to the extinction of rare species of plants and animals. They resented the extinction of the elephant in the area because there are many medicinal plants whose seeds must pass through the alimentary canal of the elephant and other animals like the porcupine and the rate mole in order to retain their medicinal properties when they germinate. According to these respondents, action must be taken in other places where deforestation has not showed its ugly manifestations so that many plants and animal species will be preserved for future generations.

\section{Deforestation and cultural practices}

Cultural practices and their manifestations are the pillars of African social life. The destruction and extinction of cultural practices destroys the moral fabric of every society while the society losses its identity (Oriega, 1992). Societies are known even in contemporary Africa because of the extent to which cultural heritage and practices are withheld by people in their different communities. Each community must have a forest reserved for cultural activities where masquerades are dressed or where members of village cults manifest their activities before exposing them in village centres during festivals for people to see, admire and even encourage youth to enrol in the cults. It was observed that deforestation by CDC has left most villages without cultural identities due to the destruction of secret forests. These observations were made in similar studies by Karumbidza (2006) in Kwazulu Natal province of South Africa where industrial tree estate had destroyed both the social and economic life of the population. Demands for indemnities by the affected populations were greeted with violence and suppression from the South African government.

According to a sixty-five year cultural advocate in Mondoni village destruction of secret forests dates back to the days of colonialism when secrets forests were regarded as places for pagan worship and did not see reasons for their existence in African communities. It is regrettable that in more than twenty villages affected by corporate farming activities none could boast of a reserve forest for cultural manifestation. Again in Ekona it was revealed that the sacred forests reserved for the performance of the Marley dance and other cultural festivals had been destroyed regardless of cultural consequences to the inhabitants.

The Marley dance which is also called the "elephant" dance was reported to be a very great festival involving all the Bakweri villages. According to the respondents who were mostly indigenous Bakweri people, Marley is a god of the people who used to be appeased through the activities carried out during festivals. It was revealed that a night before the festival was to be organized the traditional leaders consulted their god in order to seek solutions to problems encountered in the land. During the night of consultations everybody was expected to stay indoors as violators paid heavy fines in the form of money including domestic animals. Most often violators who refused to pay in fines were punished by the gods.

In Moquo village an informant recounted that:

"The company dug up our ancestral graves and planted bananas on them regardless of spiritual consequences. Perpetuators of these acts were said to have suffered and died from strange diseases which were difficult to diagnose in any health care unit".

Also the heterogeneous nature of the Moquo populations attributed to the influx of non-indigenes with different cultures have brought a mixed heritage in workers camps and the affected villages as the non-indigenes came with their own cultures and today they is a mixture of cultures in the areas where the CDC plantations are located. Due to this mixture of cultures, most people have been off rooted of their cultures and traditions with Christian practices more dominant among. Due to the dominance of 
Christianity and disappearance of forests for cultural manifestations both indigenes and non-indigenes have little time (except weekends) for cultural manifestations. Respondents also revealed that traditional wrestling which used to be a cultural activity for entertainment among the indigenous communities is declining in the absence of cultural revivals. It was revealed that secret places for men to discuss community issues have been moved to the chief's palace due to disappearance of the forest while the cultural week and village play grounds where traditional dance competition used to be organized have completely disappeared. These results are a reflection of studies by Miller (2008) on African secret societies and Cuba where expansion of industrial trees and establishment of industries lead to destruction of people's heritage.

\section{Land dispossession and consumption patterns}

One of the greatest problems resulting from deforestations and dispossession of farmland in Cameroon is changes in consumption patterns of the indigenous populations in both town and village settlements. Fako Division ranks among the most cosmopolitan Divisions in the South West Region due to the existence of employment opportunities in the Division. CDC workers camps are highly heterogeneous and serve as melting point of many cultural practices including food and nutritional requirements. According to the respondents most workers camps are plagued with series of problems with no solution envisioned. The indigenous people have found it difficult to maintain their cultural patterns due to deforestation and loss of farm land. Thus the supply of traditional food items like coco yams, plantains and yams which are staple to the indigenous people of the Division has reduced in most markets while the cost of the staples are being inflated in the wake of scarcity. Many people cannot afford for cocoyams which used to be a staple in the sixties and seventies as testified by a more than seventy five year old man at Idenau. To balance the nutritional deficiency many people have gone into the consumption of food items like maize, potatoes produced out of the South West Region. These analyses have been supported in studies by Norah (2021) on the Culture of food crop Production in Nweh, South West region of Cameroon where other food crops are cultivated alongside the traditional staples to balance nutritional deficiency in the subdivision.

The consumption of these crops is also influenced by the fact that many people in the Division are adopting new food types and food habits of people who have settled in the Division. Many of these food items are now being cultivated in marginal lands not affected by CDC activities and other areas in Fako Division which have not been significantly affected by corporate activities. These results are in line with studies by (Serah et al,2018) and (Andrianto et al; 2014) in Paraguay and Brazil respectively over farm and grazing land acquired from peasants without compensation given to indigenous people.

\section{The plantations and factory environment.}

Workers in factories visited were made up of the management staff, skilled and the unskilled workers called field workers. This category of workers are mostly unskilled labour implicated in activities such as gathering, welding, harvesting, intra-field transportation, and occasionally drivers who transport rubber or oil palm fruits and bunches into the factories. Majority of the unskilled labourers work in high risk marshy areas where they are exposed to snakes, mosquitoes and occasionally wild animals. Field work observation indicates that most workers in high risk areas and operations are not given protective clothing like boots, hand gloves and suitable clothing to protect them from harmful organisms. Respondents testified that the last time workers were given protective facilities in the company was in the late eighties and nineties. We however noticed that the most protected categories of workers are field managers, and headmen who supervise work on the plantation. Respondents explained that several workers have been victims of snake bites and attacks by other animals and insects around plantation areas which share boundaries with protected and reserve forests where the animals live. Cases were reported wherein workers died of snake bites due to the absence of transport facilities to evacuate sick patients for medical treatment. Plantation accidents are known to be common in oil palm plantations than rubber estates because animals like snakes and rat moles eat palm nuts. Encounters with snakes were revealed to be common in plantations near rivers like the Mungo and Meme river banks where plantations share boundaries with the river banks. It was revealed that during rainy seasons when the rivers are flooded the corporation losses revenue from unharvested crops as there are no embankments separating the rivers and plantations to prevent floods from entering plantations. Harvesting is therefore often suspended till the flood subsides.

One of the greatest sources of environmental problems in plantation is soil and water contamination from aerial sprays. Most human settlements are located within the plantation vicinity are victims of aerial sprays and noise pollution emanating from aircraft which affect residents and water around the settlements. In Moquo village it was observed that the buffer zone separating the banana plantation and the village from the effects of aerial sprays is only twenty five meters instead of one kilometre as standard distance (prescribed by WHO). In some communities informants revealed that $\mathrm{CDC}$ does not respect its 200 metres that is supposed to 
serve as buffers between the plantation and human settlements. Consequently, chemicals used for aerial spraying in banana plantation were said to affect human settlements especially children who usually observe or play during chemical spraying on the plantation. It was revealed in Moquo village that aerial sprays affected sources of drinking water like wells and springs due to the absence of portable water. It was revealed that aerial sprays affected the rearing of domestic animals like goats and sheep as they eat contaminated grass and die from chemical contamination. Death of domestic animals by chemical sprays has destroyed sources of income generation and rendered the people poorer.

According to the study the real impact of aerial sprays like soil and water contamination could only be made know when studies are carried out to ascertain the degree of water and soil contamination by aerial sprays as this is beyond the scope of the study. It is therefore necessary to carry out an environment and social impact assessment involving soil and water sampling around the facilities and compare with World Health Organisation standards for pollution.

\section{The factory environment and human activities}

Factory installations create undesirable environmental problems to human settlements, plants and animals when left unchecked by appropriate authorities through legislation. Factories emit gaseous and untreated effluent which are released in the air or channelled into water sources and farmlands with devastating consequences to sustainability of the environment. It was observed that most factory installations of the corporation channel untreated effluent in the sea or rivers as the case of CDC rubber factory in Tiko which is located in the middle of Tiko town and workers residential areas. The most abusive element of its location is the stench odour emanating from the factory which has remained chronic to residents of Tiko in the areas. Nick-named "Tiko perfume" the odour has become a salient characteristic of that vicinity of the town felt by visitors and residents. The impact of this odour containing oxides of sulphur and nitrogen (SO2, S03 and $\mathrm{NO} 2$ ) respectively is yet to be determined though the social, economic and environmental impacts are visible. Effluent from most factories has been channelled into creeks of the Atlantic Ocean where fish and other marine or aquatic organisms have likely been affected.

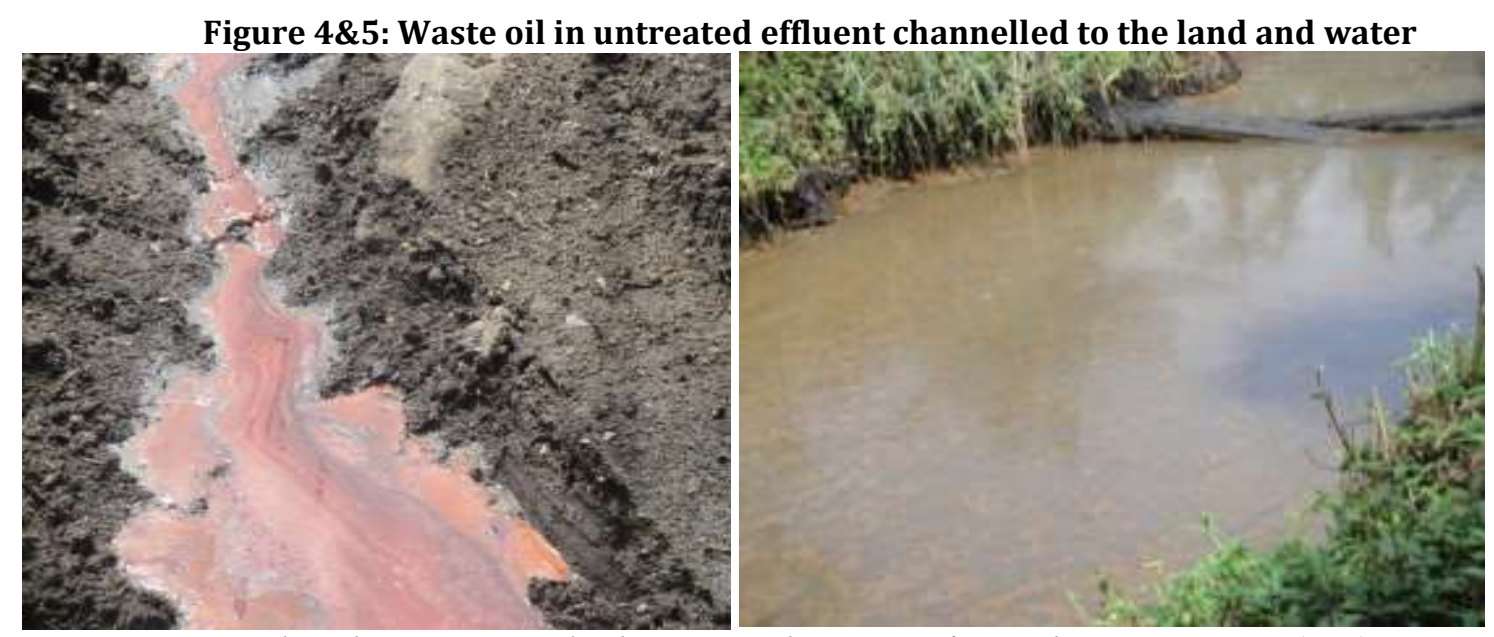

Source: Ngoe Fritz and Norah Aziamin on Social and environmental assessment of agro-industries in Cameroon (2016).

Figure 4 and 5 shows untreated effluent discharged into land and water. The effect of effluent on marine and soil organisms cannot be determined in this study because the instruments are beyond the scope of this study.

Also the present study on CDC has been limited to social issues because it was not empowered with the necessary instruments to embark on soil and water sampling including ambient air monitoring to determine the impact of emissions to plants and animals including aquatic life in the affected areas. To reduce environmental effects from liquid waste some oil palm factories have developed catchments designed to filter out waste oil from effluent for human consumption, notably for the production of soap commonly called "coco soap".

One of the best management practices identified in the factories was risk management with respect to outbreak of fire and security of the environment. Most or all factories visited have fire extinguishers and alarm instruments which go operational during fire incidents in the factory. It was equally realized that security at the entrance of every facility prevented arson from enemies who find it difficult to penetrate the factory unnoticed. However there were some risk operations that workers were 
discovered without appropriate wears. Workers who filled fire wood into boilers were not protected from heat stress, a situation which could lead to fatal health diseases and death if unattended to.

\section{Housing and accommodation in workers camps}

One of the greatest problems affecting workers in the CDC workers environment is the poor housing situation in workers camps. Except in case where residential areas are constructed as a result of development of new plantations, most of the workers camps were inherited from the German and British colonial masters at a time when population growth and migration did not constitute a problem. Residential areas for low income workers have never reflected household occupation. Allocation of residential quarters is not based on the number of household occupants but by work category with skilled workers allocated the best accommodation while the unskilled and semi-skilled workers who constitute the largest proportion of workers in the company's labour force have the lowest category of accommodation in term of facilities for decent life. Meanwhile it is this category of workers who have the highest number of household occupants or larger families. Labourers and their families live in single room apartments where cooking, sleeping, eating is done. It was observed that most of the singe rooms are divided by curtains which cover the bed from the other areas which can be used as a sitting room for leisure and dinning. Most of the rooms can hardly accommodate assets like dining table and chairs. Most of the houses were provided with a kitchen attached to the single room. As household demand for space increases some workers obtain permission to construct attachments with Indian Bamboos or wood as sleeping rooms for children or strangers or as business premises. The space provided on the corridors for cooking and laundry is inadequate while children have no place reserved as play grounds within the camp vicinity. It was revealed that a single room could contain between six to eight occupants especially when the occupants are couples with children. It is worthy to understand as revealed by respondents that the corporation housing and accommodation policies have not altered significantly from the colonial era. A similar situation was revealed by EMIS (2013) report on Environmental and social impact assessment for Pamol; another industrial tree plantation located in Ndian division of the south west region.

Figure 1: Extension of wooden houses in Ekona yard CDC workers camp.

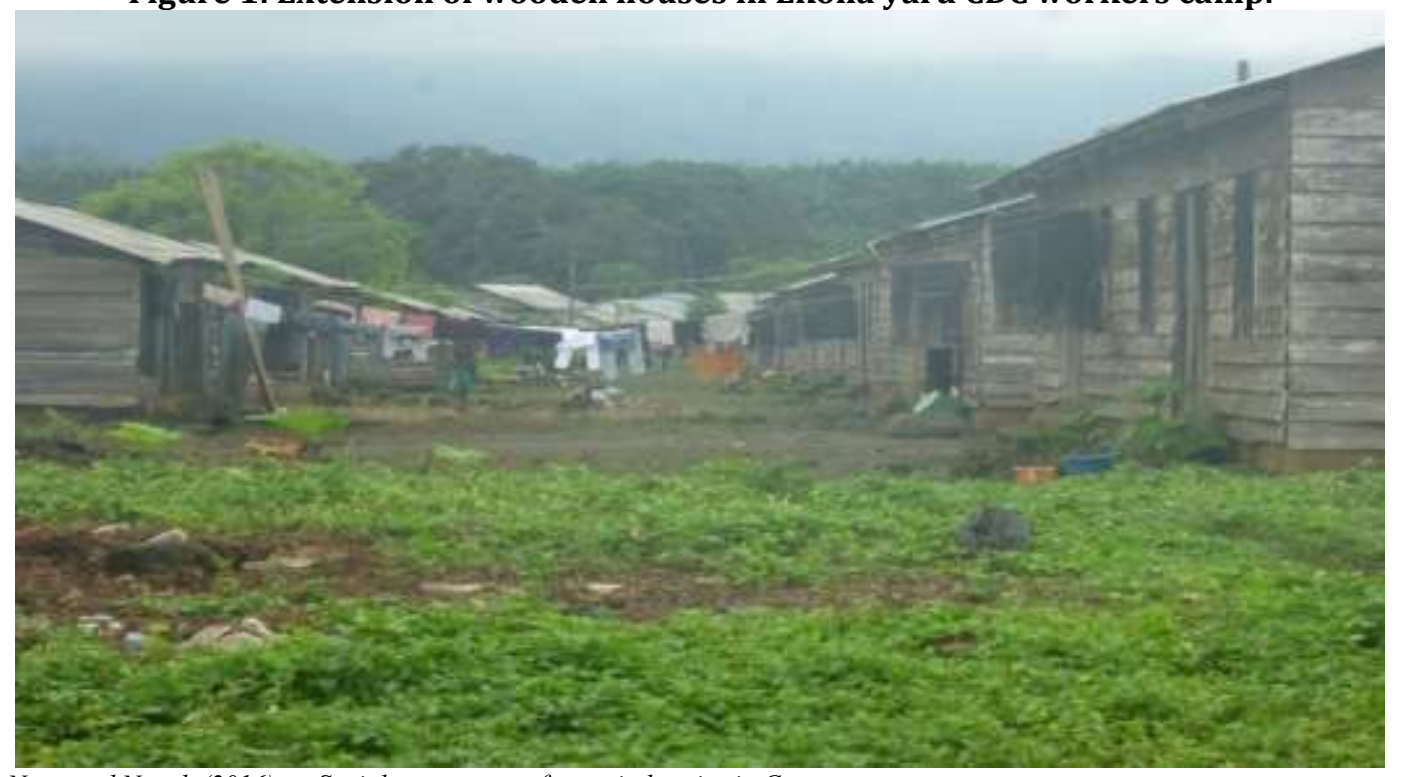

Source: Ngoe and Norah (2016) on Social assessment of agro-industries in Cameroon.

Studies by Ngoe and Manu (2016) on HIV/AIDS and Commercial Agriculture in Cameroon revealed that children develop deviant behaviour in the congested homes due to inadequate privacy as moral issues are hardly taken into consideration during house allocation to workers. Frustrations and poverty manifests in heavy drinking and drunkenness among male and female workers on pay days. Immorality and infidelity are expressed in teenage pregnancies and divorce. The use of drugs and unprotected sex are common and this has aggravated the spread of sexually communicable diseases like HIV/AIDS according to statistics revealed to CNE-MINRESI (2009) on HIV/AIDS and Public sector performance. The results of these studies indicated high prevalence of sexually transmitted diseases. Ignorance and lack of awareness was revealed as greatest factor responsible for the spread of HIV/AIDS in the company workers camps. 


\section{Hygiene and sanitation in workers camps}

Inadequate housing in Cameroon Development Corporations in workers camps reflects the state of hygiene and sanitation. Most CDC worker camps are provided with portable water. However the inability to construct new residential quarters or embark on innovations from

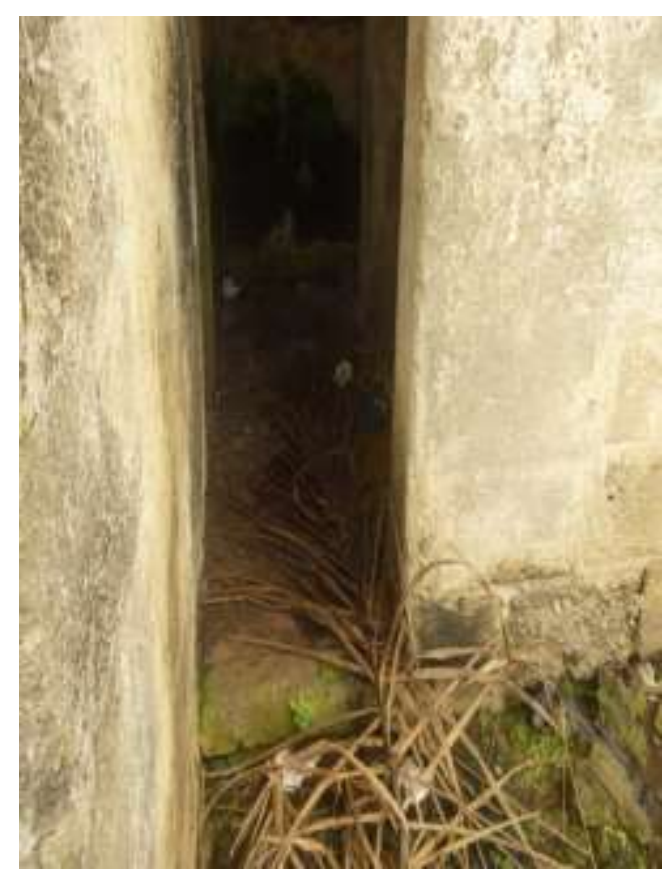

Figure 2\& 3: Unkempt and aban

The surrounding of most toilets visited were environmentally unfriendly with swamps of flies from excreta and human faeces spotted at every corner of the toilet building in uncleared grass. It was revealed that residents in workers plantations suffer from air and water borne diseases attributed to the neglected environment. Among the diseases identified were malaria, typhoid, yellow fever, cough and skin diseases. These results are a reflection of earlier studies by EMIS (2011) on environmental audit for Pamol Cameroon Ltd. The study revealed that the prevalence of disease in workers camps was partly attributed to the environmentally unfriendly nature of their residential areas.

\section{CONCLUSION}

The Cameroon Development Corporation (CDC) is the largest agro-industrial complex and next employer of labour after the Cameroon government. The corporation has vast estates of rubber, oil palms plantations, tea estates and banana plantation including facilities for processing oil palm and rubber. Although $\mathrm{CDC}$ has created employment opportunities in Cameroon and Fako division in particular it has created social, economic and environmental problems detrimental to third parties. the existing colonial structures remains a cause for concern. Toilets are also provided but overused due to high number of families allocated per toilet. Most of the toilets constructed since the colonial periods are filled as no innovations are carried out to improve on their poor sanitary conditions. Besides, cleaners rarely attend to their daily tasks and most of the toilets are abandoned with workers seeking alternative places to defecate as shown below.

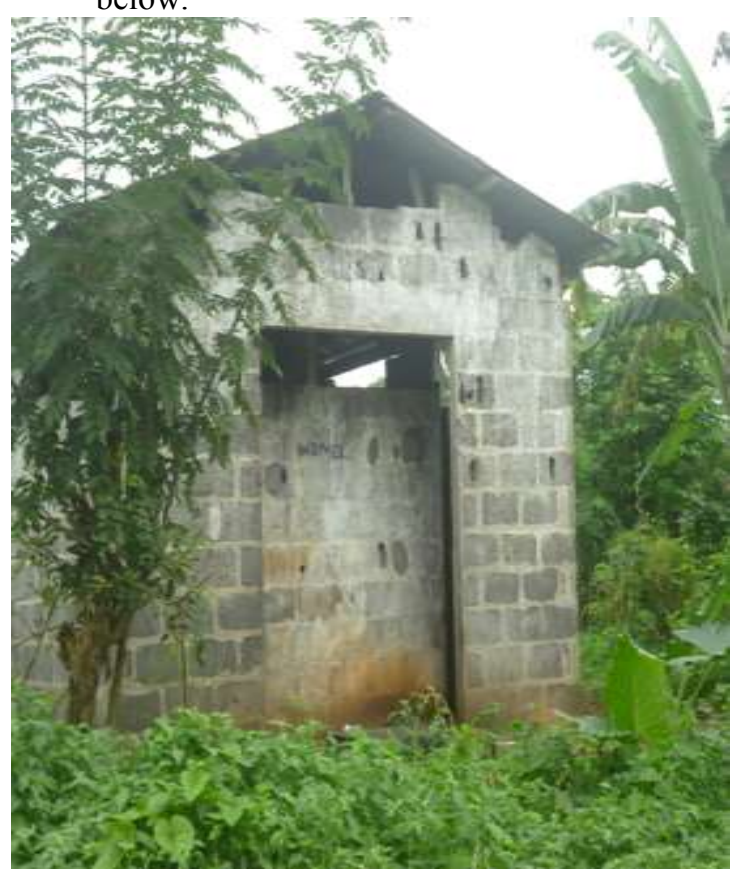

doned toilets at CDC Ekona camp.

Occupying more than half of the land mass of Fako division the corporation has occupied vast areas of land through deforestation and cultivation of industrial trees. The major disadvantage of its presence in Fako division is that areas of land meant for food production and human settlement expansion have occupied by its estates, thus reducing food supply and increasing cost of accommodation. Consequently affected town or settlements in Fako division depend on food supplies from other regions and divisions of Fako which are not affected by activities of industrial plant plantations.

Secondly all CDC factory installations produce solid and liquid waste including gaseous emitions and sound detrimental to the environment and harmful to human health and other organism and therefore limiting productive activities in the affected areas as revealed by this study. Untreated effluent channelled into sources of water, the soil and farmlands remain a great cause for concern which requires government intervention in both policy and strategies. In addition, aerial sprays in plantation have revealed disastrous consequences in human settlements including workers residential areas as observed in the study. The prevalence of diseases associated to environmental problems on land and 
water is an indication that the company is yet to give environmental issues the concern they deserve in all affected areas.

Thirdly the housing conditions of the company's workers has revealed deepening inequalities and even a violation of human rights as houses are allocated on the basis of rank and not on the number of households. It was revealed that congestion and inadequate space in living homes where couples and their children share the single rooms have been accountable to deviant behaviour among residents and the advent of sexually transmitted diseases such as HIV/AIDS among others. Inadequate housing facilities have resulted to the construction of attachment homes to relieve workers from the burden of accommodation shortages.

Finally hygiene and sanitation conditions with respect to water supply and toilets condition were observed as deplorable. Most of the toilets were unkempt and environmentally unfriendly as most workers preferred to defecate out of the toilet or the nearby estates given rice to provocative odour that may be contagious to residents.

\section{Recommendations}

This study advances the following recommendations

1) There is need for government and its agencies to put pressure on CDC to give up land for urban expansion and food production to reduce the cost of food and rentable accommodations in the affected settlements

2) The Cameroon development corporations must construct new residential homes which reflect household occupation rather than ranks in the corporation. This will reduce congestion and improve hygiene and sanitation in the workers camps including the spread of communicable conditions among residents

3) All settlements affected by CDC activities should be granted social benefits in education, health, water supply and electricity as most of the settlement lack these facilities.

4) The need to carry out environmental impact and social assessment studies to determine the real impact of waste products channeled on plants and animals including human activities.

5) There is urgent need to equip workers in high risk operations with necessary clothing to prevent them from the effects of weather conditions, snake and insect bites and from heat stress as the case of factory workers.

\section{REFERENCES}

1. Acquah E.T., Nganje W.Evange (2014). The Economics of yams(Dioscoria ssp) production in Cameroon. the case of Fako Division. International Society of Holticural Science

2. Ajayi, O.C., F. Akinnifesi, G. Sileshi, S. Chakeredza, S. Mng'omba, O. Ajayi, I. Nyoka, and T. Chineke. (2008): Local solutions to global problems: the potential of agroforestry for climate change adaptation and mitigation in southern Africa. Tropical Forests and Climate Change Adaptation (TroFCCA) Regional meeting "Knowledge and Action on Forests for Climate Change Adaptation in Africa," 18-20 November, Accra, Ghana.

3. Andrianto, A.; Sedik, B.F.; Waridjo, H.; Komarudin, H.; Obidzinski, K. (2014). The impacts of oil palm plantations on forests and people in Papua: A case study from BovenDigoel District, Paper-UR, Publication.

4. Asaah E.K (2011): Trees, agro-forestry and multifunctional agriculture in Cameroon, Yaounde

5. Baromey Neth, Sam Ol Rith, Makoto Yokohari (2012), Development without Conformity: Impacts of Large-Scale Economic Development on Indigenous Community Livelihoods in Northeastern Cambodia, International Journal of Environmental and Rural Development.

6. Cameroon Development Corporation annual reports (2017)

7. Environmental Management Initiative and Strategies(2010-2013). Report on Environmental impact and Social assessment for Pamol Installations in Ndian Division, South West Region of Cameroon.

8. Ebenezar K. Asaah, ZacTchoundjeu, Leakey RRB, TakoutsingBertin2011Trees, agroforestry and multifunctional agriculture in Cameroon, (2011) International Journal of Agricultural Sustainability 9(1):110-119

9. Dawson, Frank Place, Emmanuel Torquebiau, EricMalézieux, Miyuki Iiyama, Gudeta W Sileshi, Katja Kehlenbeck, Eliot Masters, Stepha McMullin, Ramni Jamnadass (2013): Agroforestry, food and nutritional security. Background paper for the International Conference on food security. Rome.

10. Economic and political weekly (2010): Industrial Tree Plantations in the Global South

11. Ivor .M. Miller (2008). Voice of the Leopard: African Societies and Cuba.University of Mississipi Press

12. Karumbidza J.B (2016). A study of Social and Economic Impact of Industrial Tree Plantations in the Kwazulu Natal Province of South Africa. Montevideo World Forest Movement

13. Garrity D.P.( 2004): Agroforestry and the achievement of the Millennium Development Goals. Agroforestry Systems 61: 5-17.

14. Ebenezar K. Asaah, ZacTchoundjeu, Leakey RRB, TakoutsingBertin2011Trees, agroforestry and multifunctional agriculture in Cameroon, (2011). 


\section{International Journal of Agricultural} Sustainability 9(1):110-119

15. Ingram V., Van Der Werf E, E. Kikulwe E and. Wesseler J.H.H (2014), Evaluating the Impacts of Plantations and Associated Forestry Operations in Africa-Methods and Indicators, International Forestry Review, 18(1):44-55., Commonwealth Forestry Association.

16. Ngoe Fritz Eseokwea (2020). An assessment of postharvest losses of Cassava (Manihot esculenta) in the South West Region of Cameroon; unpublished PhD Thesis, University of Dschang

17. Ngoe Fritz Eseokwea and Mary Yaya (2015). Constraints in Ameliorating Urban Habitat in Cameroon: Case of Buea Municipality. The international Research Publication: Research Journal of Social Sciences and Management (RJSSM), Vol 4, $N^{\circ} 11$.

18. Njukwe Emmanuel, O. Onadipe, Damao, $R ;$ Hanna, Hirscht, B. Maziyi-Dioxons, $A$. Mbairanodjou and T.Ngue-Bassa 2014. Cassava Processing among small-holder farmers in Cameroon; Challenges and opportunities. International Journal of Agricultural Policy Research. 2 (4): 113-124

19. Norah Aziamin Asongu (2021). The culture of food crop production in Nweh, South West Region of Cameroon; A contribution to Anthropology of Development; unpublished PhD thesis University of Yaounde 1

20. Sarah E. Brown, Daniel C. Miller, Pablo J. Ordonez \& Kathy Baylis(2018); Evidence for the impacts of agroforestry on agricultural productivity, ecosystem services, and human wellbeing in high-income countries: a systematic map protocol, Environmental Evidence volume 7 , Article number: 24 (2018) 